\title{
Gregory Ain's Mar Vista Tract Homes and the Enactment of the Public Sphere
}

\author{
GUSTAVO LECLERC \\ University of North Carolina at Charlotte
}

\begin{abstract}
The architectural and landscape design and neighborhood layout of the Mid-Twentieth Century Mar Vista tract homes by Gregory Ain and Garrett Eckbo coalesce with contemporary preservation efforts today to create a complex dynamic between groups of residents, the neighborhood as a whole, and the city of Los Angeles. As one of the first post war housing developments to receive the designation of Historic Preservation Overlay Zone (HPOZ) ${ }^{1}$, this neighborhood presents a unique set of challenges for the application of preservation principles, bringing to light questions regarding the appropriateness of enforced aesthetic principles within modernist tract neighborhoods. Utilizing Jurgen Habermas' theoretical framework of the public sphere, this paper will analyze primary and secondary data sources to consider the quality and nature of public life in this neighborhood, with particular attention to the influences of the architectural and landscape designs and the current HPOZ governance process on the enactment of a public sphere.
\end{abstract}

\section{INTRODUCTION}

Good quality design in housing can be a positive force for raising residential quality of life. Conversely, design can also be complicit in enforcing dominant politics of space use and constricting neighborhood representations. ${ }^{2}$ This case study considers how the Mar Vista tract homes' design and neighborhood layout can be understood within a minimalist framework which facilitates the creation of an engaged public space yet also as a space that resists translation from the original forms of the mid-twentieth century. The dynamic between these factors have given rise to a heightened sense of neighborliness and communication among many of its residents, and a profound sense of exclusion by others. In addition, the 'neighborhood spatial effects', including the repetition of similar housing structures, blurring between public and private spaces, and the opportunities for extensive viewing across property lines, are related to the intensity of residents' various ideological positions.

\section{MAR VISTA TRACT HOUSING}

The Gregory Ain tract housing development, completed in 1948 was a high design experiment for the working class, and part of the larger Post WW II housing boom (Fig. 1). It is representative of a then nascent utopian modernist movement. Ain, as a participant in this movement, posited that architecture could transform society for the better, and that good quality design in mass housing could dramatically influence the quality of neighborhood life. As part of a generation of socially minded architects, Gregory Ain was highly committed to architectural experimentation and to creating low cost good design for the middle and working-class populations. His architectural design concerns did not focus on creating viewing opportunities of architectural forms and scenes, but on creating theatrical zones of interactivity in which the architectural spaces would provide a context and stage for publicity. ${ }^{3}$ His collaborations with renowned landscape architect Garrett Eckbo in the Mar Vista tract homes proved to be instrumental in manifesting his philosophy. Eckbo was invested in the concept of creating gardens as common spaces for people, and felt that through their practical use and aesthetics, garden landscapes could have a positive effect on social engagement. ${ }^{4}$ Their work together in these track homes is a clear example of the experimental nature of creative practitioners in California during the twentieth century.

\section{OUTDOOR SPACES - PUBLIC AND PRIVATE}

Eckbo's landscape design incorporates conjoined lawns sprawling over adjacent front yards, evenly spaced repetitive shrubbery extending in curved lines across property demarcations, and smooth fenceless transitions between yards and the street. These attributes give the neighborhood a distinct feel of expansive public space ("public" here refers to the quality of being communally accessible to the local residents). This public quality has over time facilitated neighborhood interaction and a sense among many residents of expanded ownership and responsibility towards the neighborhood as a whole. The accessible public space of the front lawns provides neighbors with a neutral forum for gathering and exchanging ideas. These designs could also be considered precursors to minimalist aesthetic sensibilities, because their dominant feature is repetitive "non-artist made" forms, without a central convergence or symbolism. Like the architecture of the neighborhood itself, the landscaping avoids rational composition, and instead evokes the minimalist continuity of 'placing one thing after another'. ${ }^{5}$

At its most active, neighborhood interaction in the Mar Vista public space of the landscaped front yards and geometric city streets and sidewalks, is reminiscent of the ancient Greek polis, described by Jurgen Habermas as a sphere for free citizens to participate in the debates of the day, and in which inclusion was premised upon ownership and control over private (domestic) property. ${ }^{6}$ This resemblance has become more evident since the preservation effort began, and one can witness residents frequently gathering on front 


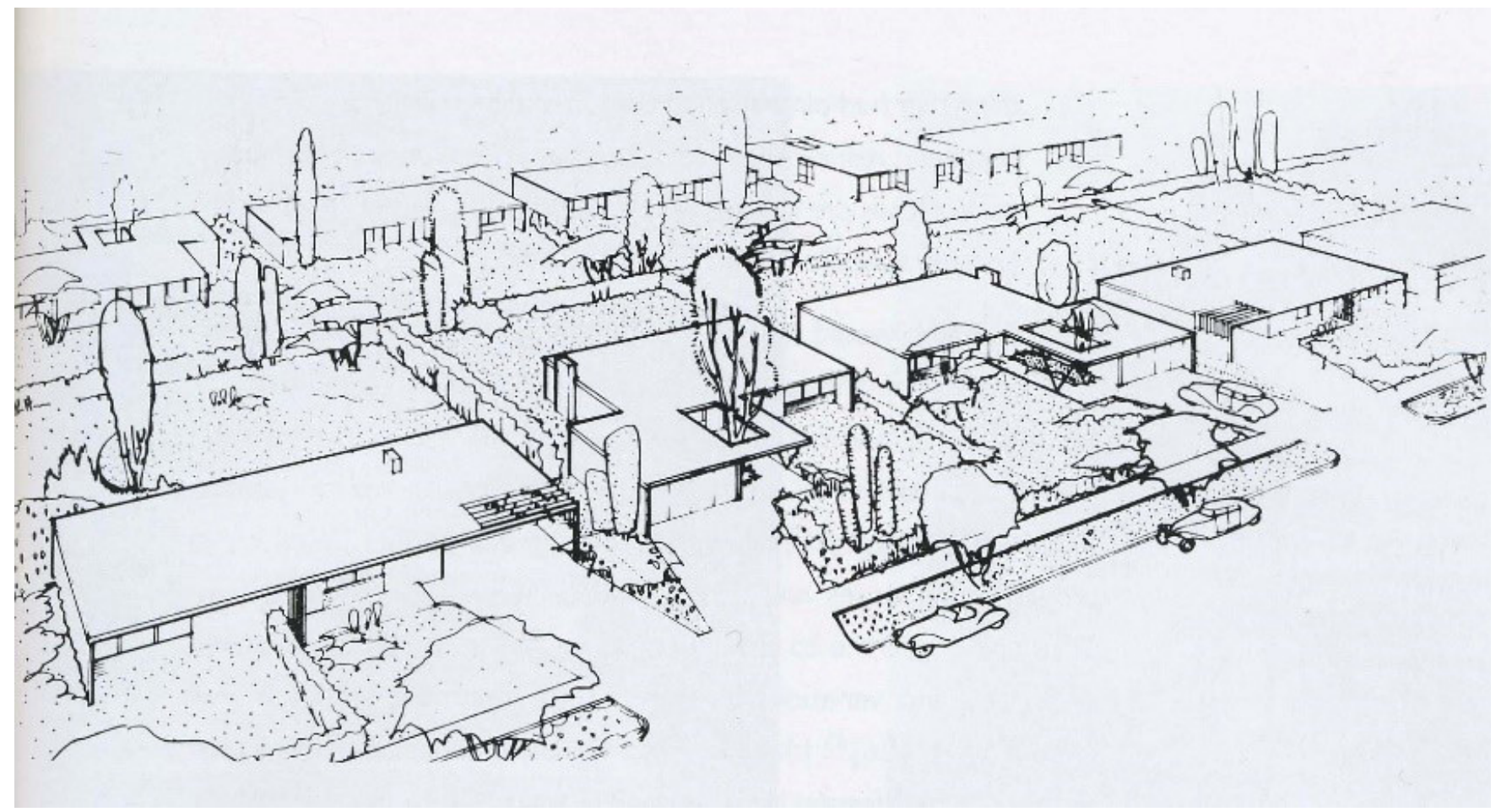

Fig. 1. Gegory Ain, Marvista Track Homes, 1948

lawns to discuss renewed interests in their homes' historical significance and their views on the neighborhood's evolution. This coalescence of human interaction, with its discourse centered on the aesthetics of its environment reflects the future minimalist concern with creating increased perceptual sensitivity in the participants of its environment. While Eckbo and Ain were not minimalist artists per se, their work in retrospect could be seen as fitting in with a minimalist framework.

Michael Fried, in his article, Art and Objecthood, denounces minimalist art for its theatrical dependency. ${ }^{7}$ Namely, that its value or meaning becomes activated only through proximity and perception of a viewer. By including the environmental space of the neighborhood as a contextual aspect of their architecture and landscape, Ain and Eckbo redefined the "frame" in which an audience can understand and participate in their work. Instead of each home and yard being evaluated and experienced individually, they are instead parts of a larger space to be experienced collectively. In the 1970's, artists further explored this reframing process, by trying to escape institutional aesthetic containers. Artists such as Richard Long and Robert Smithson created artwork in relation to specific sites such as galleries, hillsides or suburbs. While predating this artistic movement, Ain and Eckbo's landscape and architectural design based on notions of seriality and connectivity challenged similar notions as represented by property lines. This creation of architectural space in part explains residents' desire today to preserve the tract as one entity.

\section{INTERIOR SPACES - PUBLIC AND PRIVATE}

The architecture of the homes themselves contributes to this sense of expanded public space by creating extensive opportunities for viewing from within the homes to the collective "middle ground" (e.g., the yards, sidewalks, parkways, and the street itself) which runs the length of the block between opposing homes (Fig. 2).

Although Gregory Ain never explicitly referenced his design practice as socialist architecture, his ideas related to the role and value of architectural design, as well as his preoccupation with architectural projects designed for "the common man," indicates a profound commitment to an ideological progressive design approach. These ideals were rooted in the optimistic conviction that technological advances in the new industrialized society could translate into architecture. Because Gregory Ain's design philosophy prioritized function as a means to style instead of the other way around, ${ }^{8}$ his views of aesthetics were generally contrary to those of many of his designer peers.

Architects must rediscover and restore the forgotten quality of meaning to our nation's architecture...that architecture is a social art, and that its aesthetic power must be derived from a social ethos". ${ }^{9}$

\section{-Gregory Ain}

These social ideas demonstrate a developmental stage in a long-term engagement between formal artistic and architectural ideas, and social and political concerns. The minimalists, a decade later, were optimistic and somewhat utopian in 


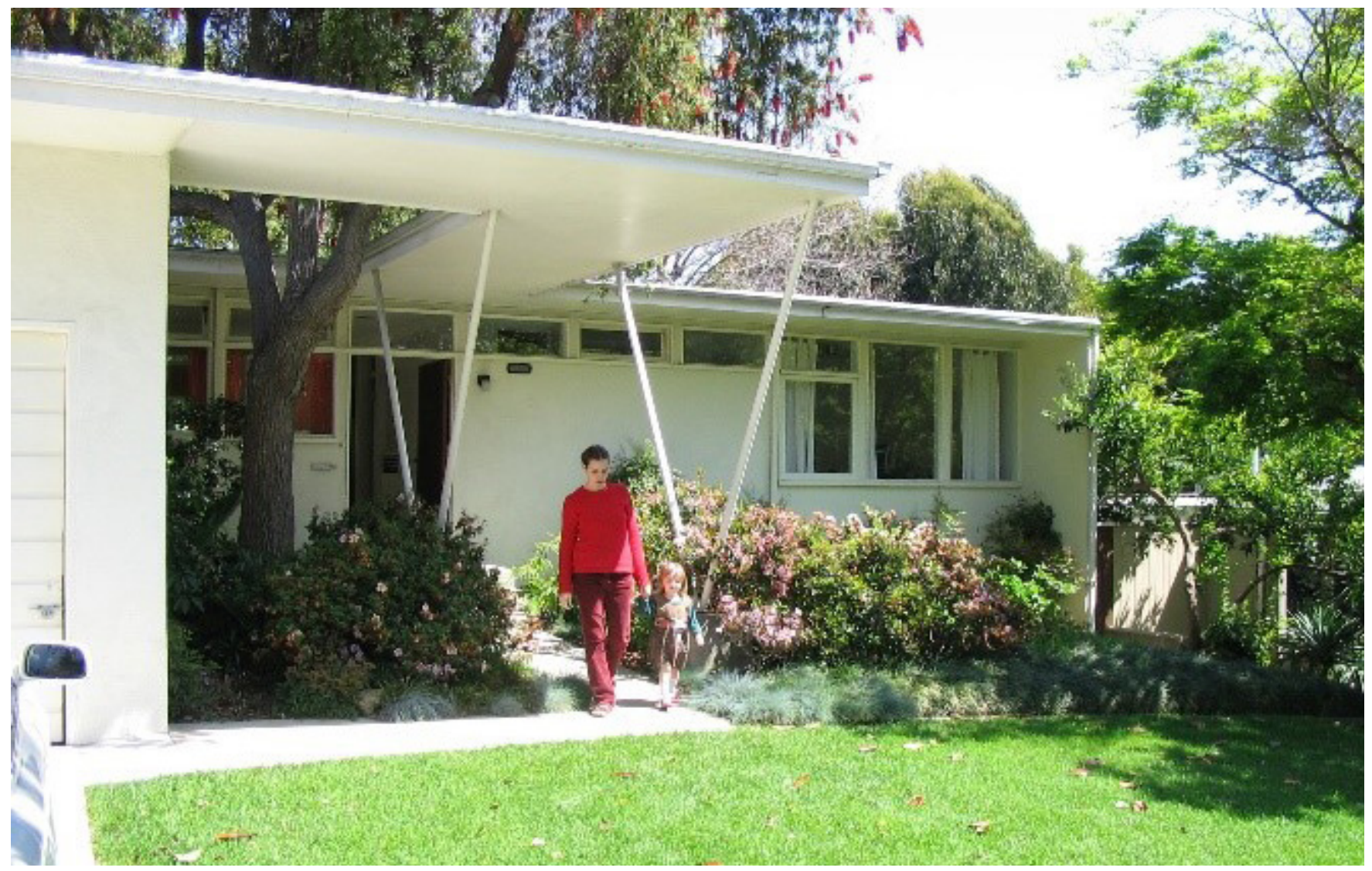

Fig 2. Front Exterior

their belief in the productive power of creative practice. Using similar strategies as Ain and Eckbo, they were invested in stimulating viewers' perceptual experience through their artwork, with the intension of increasing viewer's capacity to look and think deeply. Susan Sontag wrote in 'Against Interpretation', "Ours is a culture based on excess...the result is a steady loss of sharpness on our sensory experience. Our task is to cut back on content so that we can see the thing at all." Artists such as Sol LeWitt and Eva Hesse, believed that to increase viewers visual experience, artists needed to provide them with reduced visual stimuli, contrasting the norm of commercial culture. ${ }^{10}$ Ain's homes follow this formula in their geometric simplicity, demanding more output and interaction from the viewer, and in exchange giving them the opportunity to expand their subjective capacity.

Ain and Eckbo's concern with facilitating a sense of interactive space through their designs can also be seen as a desire to create a forum for an engaged public sphere. For Ain, this process began with repositioning traditional notions of human subjectivity to foreground the female experience, allowing formal architectural structuring to facilitate men and women's equal access to participation in the public sphere of the neighborhood.
In Habermas' definition of the public sphere, he discusses its connection to the notion of human subjectivity as a prerequisite for access. The capacity for (rational) subjectivity was determined in Ancient Greece (at the inception of the public sphere) to be present in those who had control over a domestic sphere, including one's spouse, children, servants, and slaves. ${ }^{11}$ Women were not allowed control over the domestic sphere and as such, not considered as having the same human capacity as men for rational thought and agency. Even as late as the 1960's, women's weak control over domestic spaces was linked to a perceived lack of subjective (and rational) capacity. Writers of psychoanalysis in the sixties such as Emmanuel Levinas described women as only facilitators (through provision of domestic comfort) of men's subjectivity. In the Mar Vista homes, Ain's simple repositioning of rooms and passageways between spaces, reverses traditional male-centered structural opportunities for "head of household" positioning (Fig. 3). While Ain still subscribes to traditional gender roles, he elevates the work of women by foregrounding the workspaces, and as such, allows women greater publicity and control over the affairs of the house. Habermas argues that publicness or publicity functions not as a social quality but as a status attribute. Aaron Betsky furthers this argument of theatricality by stating that it is, "only by posing one's self, that one exists."12 Over the years, women residing in these homes have taken this opportunity by positioning themselves in leadership roles within their families and in the community. As a case in point, the 


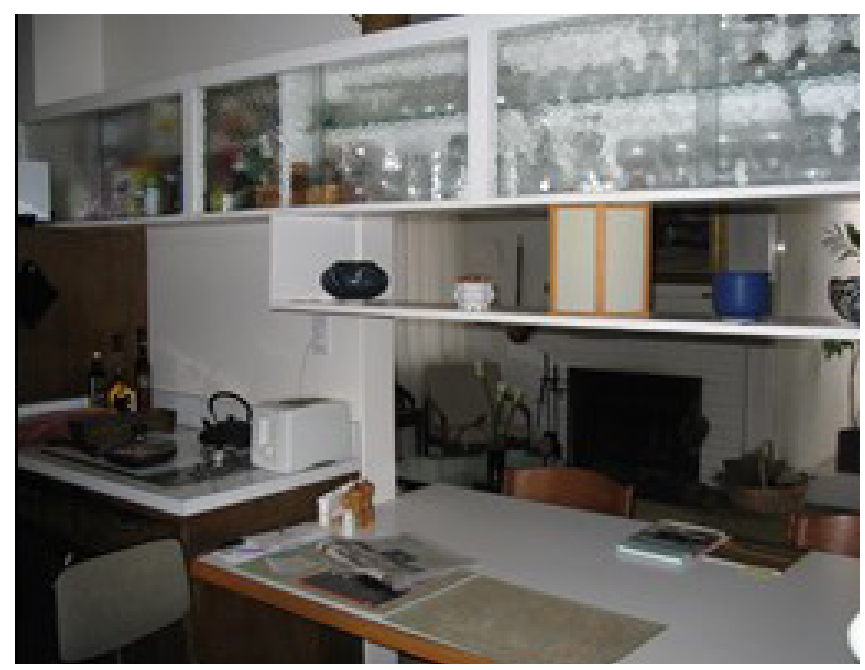

Figure 3. Kitchen and living room.

two earliest residential leaders of the HPOZ movement in Mar Vista were women. While both men and women have over time been equally engaged in the preservation process, the women frequently describe their motivation as based on a desire to preserve aspects of the neighborhood they feel impact the quality of their daily lives within their domestic environments (e.g., privacy, viewing, and interaction opportunities). Conversely, the men interviewed describe this sentiment less frequently than they describe their desire to create a more lucrative investment through HPOZ status, or to preserve the homes as objects of value or attachment.

Ain supports this engagement of women as active participants in community public life by designing with the understanding that "to see" and "be seen" supports publicity, public engagement, and authority. The design fluidity in the Mar Vista homes between public and private domestic spaces and opportunities for viewing or screening enables women to establish central positions for themselves within their lived environments. ${ }^{13}$

To support public engagement for women, the homes are oriented with the kitchen as the most public space in the homes, situated next to the primary entry way and frequently exposed to the street. This orientation of the kitchen towards the front is a break from much traditional architectural design which placed the kitchen to the rear of the house in order to hide it as a gendered work area. Though portions of the homes are purposefully oriented to give residents privacy while maintaining the interiority / exteriority blend, the houses' common spaces generally remain fairly visible from the street.

Beatriz Colomina discusses architectural elements in Loos' domestic architecture that achieve this effect of purposeful viewing through the use of modified theatre boxes elevated in the center of the homes. ${ }^{14}$ While these spaces are for leisure, they are still considered distinctly female. Loos' theatre boxes have an added character of implied sexuality, which is distinctly absent from Ain's kitchens. This is in part a result of Ain's operationalization of woman's roles within the home as both worker and primary resident. The Mar Vista homes appear as dwellings to be experienced through daily domestic rituals, and women as conductors of these rituals can function, not as supports for male enlightenment, but as the central subjects themselves. Through the architectural design considerations and communal landscaping, these domestic interior and exterior spaces provide both men and women with a ready-stage to participate in the public sphere of their community.

\section{COMMUNITY GOVERNANCE AND DISCOURSE}

HPOZ in Mar Vista. began in the late 1990's by a few residents to preserve the entire Gregory Ain tract of 52 homes through pursuit of HPOZ designation. The HPOZ (Historic Preservation Overlay Zone) is a designation given by the local governmental agencies under the guidelines of the federal government to protect and enhance areas considered unique and irreplaceable assets. At the initial stage of procuring HPOZ status, 92\% of residents supported the effort through signing a petition. Many residents shared the view that their quality of life was directly impacted by the overall neighborhood character and by maintenance of the original neighborhood layout. Based on interviews and letters, three preservation areas seem to be common priorities among residents. These include the preservation of privacy through restricting two story additions; the preservation of shared green space through the restriction of building into the front yards; and the preservation of the neighborhood look and feel, through the maintenance of a modernist aesthetics on the front exteriors.

Among neighbors, there exist three groups supporting different positions in relation to the HPOZ. These groups could be labeled as "All Encompassing", "Moderately Encompassing", and "Opposed". The all-encompassing view, which is the most totalizing, perceives the role of the HPOZ as enforcing the preservation of the neighborhood character as a whole using a strict overarching interpretation, including restricting any building upwards or forwards, maintenance of a green exterior (in a modernist Eckbo style), as well as keeping a modernist façade in the style of Gregory Ain, including materials, window size, style, and scale.

Other, moderately supporting residents, view the appropriate function of the HPOZ as limiting upwards and forward building (to various degrees) for all residents, while in terms of style, serving as more of an advisory service for residents as they attempt to maintain or alter their properties in a manner consistent with a modernist aesthetic. A third "Opposing" minority group considers the HPOZ to be a divisive element in the community, with potential destructive effects for the neighborhood's future. Their primary concerns relate to the diminishing of individual control over expressions of taste and 
style in one's property, and the dominance of one cultural sensibility over others.

This difficult situation appears to be a combination affect between both the architectural design and the HPOZ. The design is complicit in this situation because of its very homogeneous character which brings like-residents together, providing them strength and ammunition, while allowing them to exclude others different than themselves. In part, the sense of sameness or seriality has created a type of uber domestic curation. ${ }^{15}$ Residents, who may in other context have been satisfied to control the presentation and aesthetics of their own homes, have an enlarged sense of territory and domesticity, which in this context, includes the whole neighborhood. The design, along with the HPOZ, makes the neighborhood appear as one whole with many repeating parts that they feel need to be in order, for the single entity to function best. As one resident stated (to paraphrase), the homes are like the teeth in someone's mouth, they all have to be nearly the same for the mouth to work right.

The "all encompassing" residents' sense of home is related not so much to property boundaries, or to interior spaces, but to viewing potential. Anthony King, in his chapter, "The Politics of Vision", discusses the cultural specificity of, "the relation of sight or vision to belief, of belief to knowledge, and of knowledge to authority." Within the Gregory Ain homes, these people's sense of home includes everything which is stylistically consistent within their line of viewing. Within their sight (including the airspace) everything becomes a part of their own domestic environment (one could interpret this as an interesting if unfortunate side effect of the modernist integration of interiority and exteriority). A resident with this enlarged sense of home environment is inclined to curate the overall aesthetic environment, including other's facades, landscaping, and relationship with the environment (scale). The Ain design facilitates this expanded domesticity by creating a basis of repetitive sameness.

Looking at this phenomenon from a positive perspective, it is also this precise sense of "we are all a part of the same thing" that evokes a sense of shared responsibility and commonality. In considering this tendency in relation to the facilitation of a public sphere, this enforcement of sameness of the publicly visible arena could theoretically consolidate a sense of a common public space vs. aspects of individual private property. In Habermas' exploration of the concept of the "public", he discusses its manifestation within the context of the ancient Greek marketplace, where free citizens could congregate and discuss the issues of the day. In lieu of many such comparable spaces in contemporary Los Angeles, the Mar Vista homes' streets and front yards could be considered an important instance of the realization of the public sphere, serving as accessible arenas for "free citizens" (aka, residents) to congregate. Aaron Betsky elaborates on the modern (or more precisely postmodern) evolution of the public sphere in his article, "Nothing but flowers: Against Public Space" where he claims that today's public spaces which contain the most active public dialogue are, "made by front lawns, driveways, turning radiuses, security perimeters, [and] lines of sight.... It is the unfenced yard and the zone lit by television." ${ }^{\prime 16} \mathrm{He}$ continues on to state that these unregulated spaces redefine traditional public discourse by embracing those historically excluded such as women, people of color, and gays and lesbians. Habermas' clarifies though, that the public sphere represents not just occurrences in a specific locale, but a sphere that "was constituted in discussion" and implicitly, with the free exchange of ideas.

Resident with "moderately encompassing" views of the role of the HPOZ in residential regulation, frequently state that the shared green space is the most important aspect of the neighborhood to preserve. This idea is consistent with many residents' explanations of what first drew them to the neighborhood, specifically, the integration of modest setback homes within a shared garden like setting. This enclosed sense of a common garden promotes the quality of the neighborhood as a unit. Interestingly, these residents consider the air space above their homes as much public space as that on the ground level. One could argue that this sense of peaceful enclosure provides isolation from the rest of the city, and as such, safety and special status. Many residents' comments give the impression that they consider their neighborhood to be an oasis within the larger hostile urban environment. This in part would explain why residents show negligent concern over the affairs of the surrounding neighborhood beyond the "enclosed" three-block radius. This sense of common enclosure could also be a positive force promoting the development of the public sphere which is premised on its participants feeling safe to express their views. Many of the interviewed residents responded that after living in the homes, they have developed positive, close relationships with many of their neighbors.

The two related ideas of preserving shared green space and restricting two story editions relate directly to community's quality of life. The third aspect of preservation is related to style and does not directly impact quality of life issues such as scale, access, or greenery. Ironically, this aspect is the most closely aligned with the HPOZ mission of preserving the character of important architectural buildings. This is because it is only through the determination of the neighborhood as representative of a valued architectural style that it achieves elevated status and provides added cultural capital for the city. It is also the preservation aspect most strongly endorsed by the "all encompassing" camp of residents and one which is the most contentious in this context. The importance of style is also consistent with a minimalist agenda, with a focus on exteriority and surface. 
People have a variety of views towards how closely they believe their aesthetic choices need to adhere to Gregory Ain or Garrett Eckbo's original design. The issue of style, while not obviously related to interaction or space issues, does relate to issues of prestige and authority, both of which are important in determining one's access to, and the weight of one's comments within the public sphere. This prestige and authority could translate to the localized public sphere of the neighborhood as well as the larger citywide, national, or international public spheres concerned with culture and style. Habermas, in describing the vested authority of 18th century European nobility, claims that authority was both an outcome of, and prerequisite for, its public displays of style. The enactment of style became the mark of "good society", a fact which remains true today. Though not to the same exclusive degree, it often is a necessary precursor for access to realms of elite society. This symbolic passport may very well be a motivating factor for both residents and the city to preserve the neighborhood's modernist style, and an argument for why this quality takes precedent over other quality of life issues related to everyday experience. It also is evidence of the elevated status of modernist works in general and minimalist works in particular today, which have ironically slid easily into commodity culture.

The minimalist nature of the Ain and Eckbo housing design in Mar Vista has led to an interesting situation today where residents are often confused about how much to understand their neighborhood as a single entity in adherence with its minimalist quality, and how much to consider each home as individual, separate entities. While Ain and Eckbo's design efforts in Mar Vista predated the minimalist project by over a decade and are transdisciplinary in nature, their work fits into its sensibility and framework through its use of repetition of elements, is lack of a central "internal core", and its focus on exterior, unsymbolic structures. In this way one can see how the boundaries of artistic movements, in truth, represent the critical mass of long terms trends which ebb and flow within and across disciplines.

The Mar Vista neighborhood provides an example of how the preservation zoning of neighborhoods has the powerful potential to position them within the frame of visual arts' space, and as such, as semi-static exhibitions instead of evolving living environments. While display and performance can be important vehicles for enacting the public spheres of these neighborhoods, creating a balance between preserved space and lived space appears to be a challenge. While residents can benefit in numerous ways from the HPOZ, they could suffer by no longer constituting the neighborhoods' primary public, which now includes all residents of the city who have a vested interest in the city's cultural capital. This change in goals and focus indicates that the primary role of residents in the HPOZ neighborhoods is considered by the city to be as facilitators of a city artistic display. While this function may often overlap with what is also in the best interest of residents, decisions meant for architectural preservation will not have as their central concern, the quality of life of current residents. Because of this shift, neighborhoods in preservation or HPOZ districts, such as the Mar Vista tract homes, lose a certain level of agency needed to make decisions for their own "greater good."

This shift in focus away from the human element of a community to the material element, has led HPOZ neighborhoods to tumble along a trajectory towards petrifaction. This adds an interesting twist to the minimalist conceptualization of artistic space when one considers its application within the Mar Vista homes. The minimalists considered the human element as primary aspects of their work, but only as transitory subjects within the frame, not as permanent installations. In part, the philosophy behind minimalist art which informs the appreciation of the Mar Vista homes today is only a partial fit, not fully accommodating the transition in context from art into architecture. As a result, in Mar Vista, instead of reaching the goal of returning the neighborhood to its roots where good style existed to facilitate good quality of life, the neighborhood is in jeopardy of ending up as mimicry of itself, a clumsy disguise upon a divergent core.

As HPOZ efforts potentially "harden" neighborhoods in time by increasing their fixity within specific cultural and temporal frameworks, residents can establish positive dialogue with one another regarding the direction of their neighborhoods and work to ensure that their domestic environments continue to meet their needs. The challenge is not to suppress diverse tastes and aesthetics in this process but to move towards the goal of promoting equal social connectivity, even at the expense of compromising artistic integrity. Residents in Mar Vista could remember in their current preservation zeal that Ain and Eckbo's original design was informed by the belief in flexible uses of space, evolving notions of private and public, and responsiveness towards the temporary conditions of neighborhood life. Because the HPOZ process carries the risk of distancing neighborhood residents from their physical environment by diminishing their ability to mold it, residents in these communities would be served best by working together to build vibrant communities based on the creation of productive, inclusive public spheres.

\section{REFERENCES}

1 Chow, Renee Y. "Unpacking," in Suburban Space: The Fabric of Dwelling (Berkeley \& Los Angeles: University of California Press, 2002).

2 Colomina, Beatriz. "Interior," in Privacy and Publicity: Modern Architecture and Mass Media. (Cambridge, MA: MIT Press, 1994).

3 Cuff, Dana. "V. Whose Dream, America? and VI. Convulsive Suburbia: Westchester," in The Provisional City: Los Angeles Stories of Architecture and Urbanism. (Cambridge, MA: The MIT Press, 2000).

4 Fried, Michael. Art and Objecthood, (University of Chicago Press, 1998).

5 Gebhard, David. The Architecture of Gregory Ain. (Santa Barbara, CA. The Regents University of California, 1980).

6 Giddens, Anthony. "Introduction," in The Consequences of Modernity. (Stanford, CA: Standford University Press, 1990) 
7 Habermas, Jurgen. The Structural Transformation of the Public Sphere. Cambridge, MIT Press, 1991

8 Hayden, Dolores. "Shape of Suburbia," in Building Suburbia: Green Fields and Urban Growth, 1820-2000. New York: Pantheon Books, 2003

9 King, Anthony. "The Politics of Vision," in Understanding Ordinary Landscapes. Paul Groth and Todd W. Bressi, eds. New Haven \& London: Yale University Press, 1997

10 Krauss, Rosalind E. Passages in Modern Sculpture, The MIT Press, Cambridge, MA, 1977

11 Lavin, Sylvia. “The Temporary Contemporary," in Perspecta 34, 2003

12 Levinas, Emmanuel. "The Trace of the Other," in Deconstruction in Context: Literature and Philosophy. Mark C. Taylor, ed. Chicago, II: The University of Chicago Press, 1986

13 _-_ "The Dwelling," in Totality and Infinity: An Essay on Exteriority. Pittsburgh: Duquesne University Press,1969

14 Reed, Peter S. "Enlisting Modernism," in World War II and the American Dream. Donald Albrecht, org.\& ed. Washington, DC: National Building Museum; Cambridge, MA: The MIT Press, 1995

15 Treib, Marc and Imbert, Dorothee. Garrett Eckbo: Modern Landscapes for Living. Berkeley: UC Press, 1997.

16 Zellman, Harold, and Roger Friedland. "Broadacre in Brentwood?: The Politics of Architectural Aesthetics," in Looking for Los Angeles: Architecture, Film, Photography, and the Urban Landscape. Charles G. Salas and Michael S. Roth, eds. Los Angeles: Getty Research Institute, 2001

17 Notes

1 An Historic Preservation Overlay Zone, or $\mathrm{HPOZ}$, is an area of the city which is designated as containing structures, landscaping, natural features or sites having historic, architectural, cultural or aesthetic significance. Once designated, areas have an HPOZ overlay added to their zoning, and are subject to special regulations for new buildings and/or modifying any structure within the HPOZ area.

2 Chow, Renee Y. "Unpacking," in Suburban Space: The Fabric of Dwelling. Berkeley, Los Angeles: University of California Press, 2002.

3 Gebhard, David, Von Breton, Harriette, and Weiss, Lauren. The Architecture of Gregory Ain: The Play Between Rational and High Art, Santa Barbara, CA, UC Press. 1980.

4 Treib, Marc and Imbert, Dorothee. Garrett Eckbo: Modern Landscapes for Living. Berkeley: UC Press, 1997.

5 Krauss, Rosalind E. Passages in Modern Sculpture, The MIT Press, Cambridge, MA, 1977: 244.

6 Habermas, Jurgen, Structural Transformation of the Public Sphere, Cambridge, MIT Press, 1991.

7 Fried, Michael. "Art and Objecthood", (1967), in Minimal Art: An Anthology, pp 116-147

8 Joselit, David, American Art Since 1945, London, Thames \& Hudson World, Ltd. 2003.

9 Gebhard, David. The Architecture of Gregory Ain. Santa Barbara, CA. The Regents University of California, 1980.

10 Joselit

11 Habermas. 1966

12 Betsky, Aaron. "Nothing but Flowers: Against Public Space," in eds. Michael Bell and Sze Tsung Leong Slow Space, 1998.

13 Colomina, Beatriz."Interior," in Privacy and Publicity: Modern Architecture and Mass Media. Cambridge, MA: MIT Press, 1994

14 Ibid.

15 For more information on the concept of domestic curation, see Sylvia Lavin's essay "The Temporary Contemporary," in Perspecta 34, 2003

16 Betsky, Aaron 